\title{
Going Squirrelly: Evaluating Educational Outcomes of a Curriculum-aligned Citizen Science Investigation of Non-native Squirrels
}

\author{
Heather Spicer, Daniel Nadolny and Erin Fraser
}

\begin{abstract}
We report on the educational outcomes of the Newfoundland Squirrel Project (NSP), a citizen science project conducted by schoolchildren in Newfoundland, Canada. The NSP was developed with the charitable organization Let's Talk Science (LTS), and involved students surveying non-native red squirrels (Tamiasciurus hudsonicus) and eastern chipmunks (Tamias striatus) using silent observation, call broadcasts, and interviews of the general public. We aimed to (1) provide equitable access to this science outreach opportunity for classes across rural Newfoundland, regardless of remote location; (2) evaluate the likelihood that participants would have firsthand encounters with live animals; and (3) investigate changes in students' perceptions that participation in science satisfies the psychological needs of autonomy, competence, and relatedness, which are all components of motivation. We further tested whether these changes correlated with changes in enjoyment of and future intentions towards participating in science. The proportion of participating schools classified as rural did not differ from that of all Newfoundland schools, suggesting that rurality did not impede participation. Participants commonly encountered squirrels. There were limited changes in participants' perceptions of science as satisfying psychological needs. Increases in perceived science competence predicted increases in future intentions to participate in science. We conclude that aligning the NSP with the school curriculum was an effective way to deliver science outreach to students in rural environments and that squirrel surveys provide an impactful experience, as participants often closely encounter these animals. We recommend further research exploring how participation in citizen science impacts participant perceptions of science competence and pursuit of future science activities.
\end{abstract}

Keywords: elementary school students; motivation; Newfoundland; science outreach; rural; squirrel surveys

\begin{abstract}
Introduction
Public participation in scientific research (PPSR) can result in positive social outcomes for participants (Bonney et al. 2016), including changes in scientific awareness/knowledge, engagement, attitude, behaviours and skills (Bonney et al. 2009). Public participation in scientific research can influence participants' knowledge of their study system (Brossard, Lewenstein, and Bonney 2005; Evans et al. 2005), science literacy (Cronje et al. 2011), ability to understand and engage in the scientific method (Trumbull et al. 2000), and conservation actions (Devictor, Whittaker, and Beltrame 2010). Most research investigating the social impacts of PPSR is focused on adult participants, although some work has focused on youth and young adult participants (Kountoupes and Oberhauser 2008; Hillier and Kitsantis 2014; Vitone et al. 2016; Ballard, Dixon, and Harris 2017). Youth may engage with PPSR through both
\end{abstract}

Memorial University of Newfoundland (Grenfell Campus), CA Corresponding author: Erin Fraser (efraser@grenfell.mun.ca) extracurricular activities and when PPSR projects are embedded in the school curriculum.

In many PPSR projects, participants self-select for involvement and are often not broadly representative of the population (Evans et al. 2005; Pandya 2012). This is troublesome, as participation in PPSR can facilitate participant pursuit of science-based careers and may be an enriching experience for a broader segment of the population than only those who self-select to participate. Bonney et al. (2016) identified "curriculum-based projects" (p. 4) as a category of citizen science - one form of PPSR - that has the potential to facilitate engagement of new audiences. In such projects, students from a wide range of demographic backgrounds (including elementary through higher education), from a range of socio-economic backgrounds, and with varying pre-existing interests, have the opportunity to engage in an authentic scientific process.

Recent work in PPSR identifies that participant motivation, the underlying psychological reason for behaviour, has largely been overlooked as a learning outcome (Phillips et al. 2018). In particular, Phillips et al. (2018) call 
for more research on changes in motivation over time following participation in PPSR, and how these motivations relate to the theories and findings of self-determination theory (SDT). SDT posits that people are motivated by activities that fulfill three basic psychological needs: autonomy, the need for freedom and control over the course of action; competence, the need for gaining or using skills to effectively exert control over outcomes; and relatedness, the need to connect with others (Deci and Ryan 2012). When these three needs are fulfilled, people experience greater internal/intrinsic motivation (Ryan and Deci 2000), greater intentions to persist in science (Lavigne et al. 2007), and more optimal learning occurs (Niemiec and Ryan 2009).

Previous work reveals that people set goals in areas of their life that vary in how much they provide the opportunity to fulfill autonomy, competence, and relatedness needs. Goals set in areas that satisfy these needs are more likely to be self-concordant goals, or goals that align with our values and true self (Milyavskaya, Nadolny, and Koestner 2014). Self-concordant goals are particularly beneficial, and are more likely to be successfully completed, compared with other types of goals.

We hypothesize that engagement in PPSR projects may change participants' perceptions that science offers ways to fulfill these three psychological needs, which may then lead to adopting science goals. Participants may gain a greater sense of autonomy in the scientific process by having the opportunity to make decisions related to a research project. They may gain a sense of competence in science through successfully participating in an actual science project, through conducting real scientific work. Finally, they may realize that science is something that can be done in collaboration with friends and classmates as they work together with other participants, resulting in an increase in perceived relatedness. Perceiving science as satisfying these needs may then contribute to greater interest in future scientific endeavours, and enjoyment of science.

We present a case study describing some of the programmatic and individual learning outcome goals (Jordan, Ballard, and Phillips 2012) of a curriculum-aligned citizen science project targeted at students in grades four to eight in Newfoundland and Labrador, Canada (hereafter referred to as the Newfoundland Squirrel Project, NSP). In a class setting, students investigated and reported on the distribution and abundance of non-native red squirrels (Tamiasciurus hudsonicus) and eastern chipmunks (Tamias striatus) across the island of Newfoundland and some offshore islands. The NSP operated as part of Let's Talk Science (LTS), a national charitable organization that states its mission as "dedicated to helping prepare Canadian youth for future careers and citizenship demands in a rapidly changing world," and so the NSP shared many of the programmatic goals of LTS. LTS provides support for educators through professional learning and easy-toaccess online resources, and it gives youth the opportunity to participate in classroom outreach, national science experiments, and interactive events (letstalkscience.ca). A particular objective of LTS is to provide equitable access to programming, and the organization has a mandate to provide STEM (Science, Technology, Engineering, and Math) outreach to youth in rural communities. Equitable access to informal science STEM opportunities is a well-documented challenge (Dawson 2014), and rural communities may have limited access to these types of programming (Avery 2013). Access to outreach in remote communities is a particularly important issue in Newfoundland and Labrador, where a substantial proportion of the population lives in rural areas.

We report on two key programmatic outcome goals of the NSP: to provide science outreach activities to any interested elementary school classes in Newfoundland (regardless of remote, rural location) in the form of participation in an ecological research project; and to give participating students the opportunity to gain familiarity with their local ecosystems through firsthand observations of wildlife and local habitat features. Further, we report on an individual outcome goal: to promote participants' future interest in science and enjoyment of science. We assess this through an exploration of how participation in the NSP may impact participants' motivation through changes in their perceptions of science as satisfying the essential psychological needs of autonomy, competence, and relatedness (Deci and Ryan 2012). Finally, we aim to test how changes in perceptions of psychological needs satisfaction predict future intentions in science and enjoyment of science. Given the current emphasis on making STEM subjects accessible to girls, we report gender effects where relevant.

\section{Methods}

\section{LTS-STEM outreach in Newfoundland}

LTS operates as a network of sites at university and college campuses across Canada and relies on volunteers and some paid staff to offer diverse programming. Let's Talk Science programs include, but are not limited to, in-person, volunteer-led events such as classroom visits, on-campus events, and activities at community events; online activities; free educator resources; and classroombased science projects. Equitable access to LTS outreach programming is particularly challenging in Newfoundland and Labrador. Approximately 520,000 people live in the province of Newfoundland and Labrador, and more than $40 \%$ of them are in rural locations (Statistics Canada 2016). The term "rural" is widely used in academic literature and has many definitions (Sipple and Brent 2015). Unless stated otherwise, in the present study, we refer to rural outreach according to the definition presented by the LTS organization, which is an outreach activity occurring in an area $>35 \mathrm{~km}$ from an urban centre. Rural settlements in Newfoundland are widely dispersed and many are accessible only by ferries/planes or by poor roads. Long, harsh winters make travel difficult for many months each year.

There are two LTS sites in Newfoundland and Labrador, both at campuses of Memorial University of Newfoundland, located in the two largest urban centres in the province. Seventy-two percent of schools in Newfoundland and Labrador are located in communities with a population less than 20,000 and are more than $35 \mathrm{~km}$ from an LTS site. Fifteen percent of schools are located in areas that require ferry or plane access from the nearest LTS site. Access issues can make in-person outreach activities very 
challenging, and it is difficult to provide the same amount and quality of science outreach opportunities for rural youth as their urban counterparts experience (Figure 1).

\section{Newfoundland Squirrel Project (NSP) - background and scientific objectives}

Newfoundland is a large $\left(>100,000 \mathrm{~km}^{2}\right)$ island in Canada and historically had a depauperate mammal fauna. Over the past 200 years, 11 additional mammal species have successfully been introduced (Strong and Leroux 2014), with successful introductions of non-native $T$. striatus and T. hudsonicus in 1962 and 1963, respectively (Newfoundland and Labrador Department of Fisheries and Land Resources; Whitaker 2015). T. hudsonicus were introduced to or translocated within Newfoundland and the near-shore islands multiple times before 1975. These movements were made by citizens and members of the provincial government, and the rationale included the addition of a new prey species for Newfoundland marten (Martes americana atrata); an additional species for fur trapping; and for enjoyment (Whitaker 2015). Recent evidence suggests that the introduction and subsequent spread of T. hudsonicus in Newfoundland has had major impacts on several species of local plants and animals. Tamiasciurus hudsonicus are seed predators and, when abundant, may interrupt the regular regeneration of coni- fers such as native balsam fir (Abies balsamea) (Gosse et al. 2011). Further, they may have deleterious effects on the Newfoundland subspecies of some birds, such as competing for food with the endangered Red Crossbill (percna subspecies) (Loxia curvirostra percna) (Benkman 1993) or predating the nests of Newfoundland Gray-cheeked Thrush (Catharus minimus minimus), another species at risk in Newfoundland and Labrador (Whitaker, Taylor, and Warkentin 2015).

There is little work investigating the impacts of $T$. striatus on Newfoundland ecosystems. Prior to the NSP, species distribution and abundance of both species were not well documented in Newfoundland, and there was a need to gain information about their extents across insular Newfoundland and the near-shore islands. T. hudsonicus are highly territorial, and individuals will respond to conspecific vocalizations (calls), often approaching the point from which the call originates. This makes it relatively easy for the average citizen to determine squirrel presence, both through silent observation and by observing squirrel responses to call broadcasts using a speaker.

\section{Project implementation}

Between June and September 2016, teachers and schools from the Newfoundland and Labrador English School District (NLESD) were contacted by phone and e-mail and

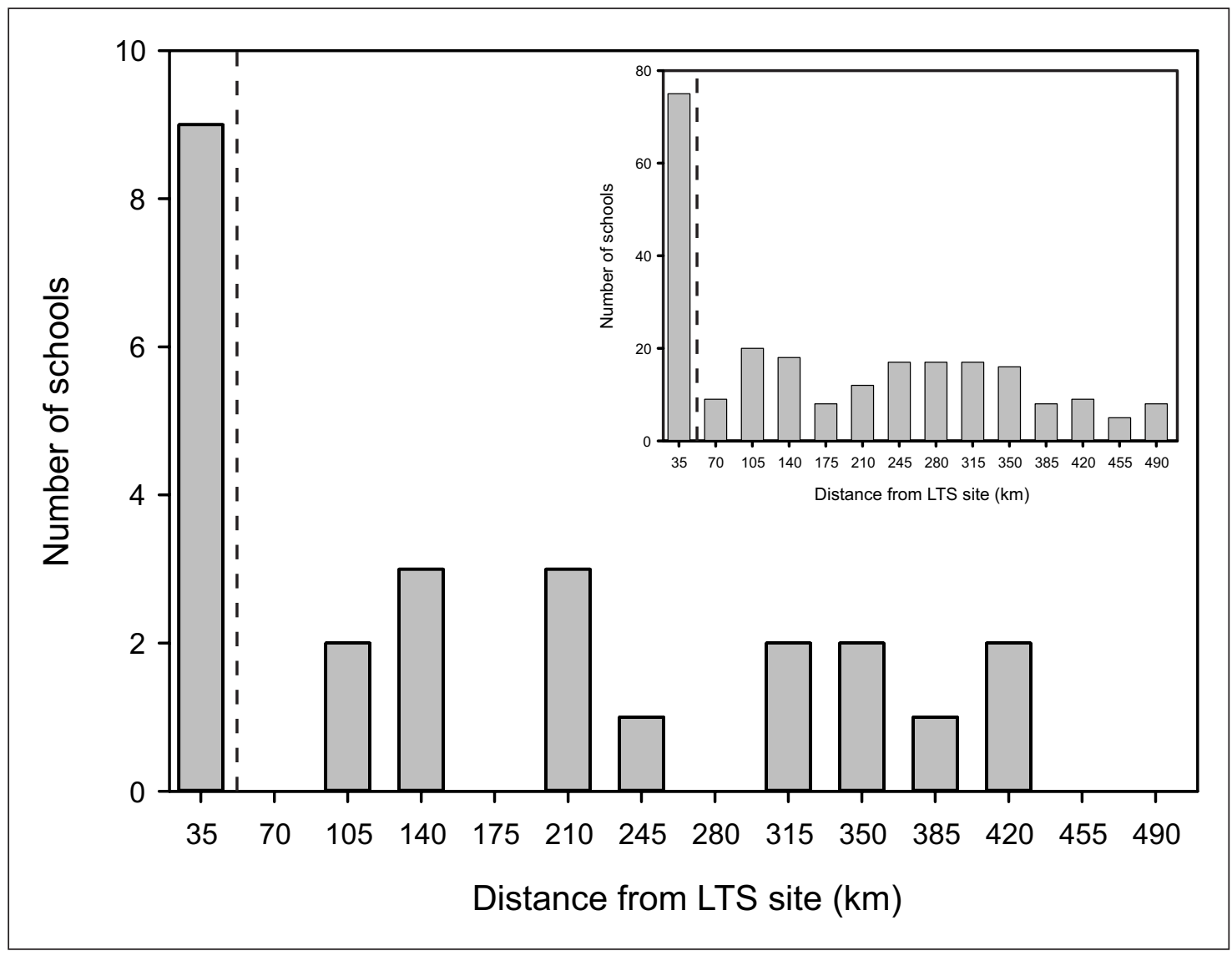

Figure 1: Distance distribution of Newfoundland schools from the nearest Let's Talk Science (LTS) site. The distribution of schools located varying distances from an LTS site (in Corner Brook or St. John's) participating in the Newfoundland Squirrel Project (main figure) is similar to the distance distribution of all schools in the Newfoundland section of the Newfoundland and Labrador English School District (inset). Dashed lines indicate the cut-off between rural and nonrural schools (where rural is defined as being $>35 \mathrm{~km}$ from a city centre), and there is no difference in the proportion of total schools classified as rural between the participating and total groups $(p=0.599)$. 
invited to participate in the NSP. Because the two squirrel species of interest were introduced only to insular Newfoundland and the near-shore islands (i.e., they are native [T. hudsonicus] and not present [T. striatus] in mainland Labrador), only teachers at schools in Newfoundland and the near-shore islands were invited. All participating classes were between grades four and eight.

A condition of our agreement with the Newfoundland and Labrador English School District to engage classes in the NSP was that participation in the research would not negatively impact instructional time for students and teachers. We designed the project with this in mind, and so made a conscious effort to make the citizen science data collection relevant to the science curricula of the participating classes. To achieve this, we designed a series of free accompanying educational activities that linked Newfoundland squirrel biology to one topic in the provincially mandated science curriculum for each participating grade (complete list provided in Supplemental File 1, Teacher's Guide to the Newfoundland Squirrel Project). For example, a fourth-grade science curriculum component was to learn about food chains and habitats, and participating classes were provided with an activity to help them build a Newfoundland-specific food chain that could include the study squirrel species; a fifth grade curriculum component was to learn about animal body systems and the accompanying educational activity was a body insulation experiment to demonstrate how fur helps squirrels and other small mammals survive the long, cold Newfoundland winters.

Each participating class received a package containing a written teacher's guide (Supplemental File 1), which included a welcome letter, some background information, letters to parents, instructions for data collection, data sheets, a list of hands-on educational activities to relate the science curriculum of each grade to local squirrel biology, and a copy of the relevant provincial wildlife permit; a wireless speaker (Staples XTREME Audiopod portable Bluetooth Speaker); and supplies to complete the educational activity relevant to the grade of the participating class. Data sheets were simplified and standardized, using checklists and short answer questions that ideally reduced inter-observer variation (Holck 2008; Snäll et al. 2011; Lewandowski and Specht 2015) and project updates were regularly e-mailed to participating classes over the course of the data collection period. Detectability of T. hudsonicus in response to the broadcast of conspecific territorial calls likely varies seasonally (Warkentin et al., in prep), so we limited data collection to a three-month period in autumn. Packages were distributed in October 2016, and data sheets were returned in December of the same year.

Participating classes were given the option to collect data in any or all of the three following ways: $(i)$ class point count/call broadcast survey, (ii) individual walk in the woods, and (iii) interviews with family and friends. To assist participants in identifying the species of interest, colour photos of both $T$. hudsonicus and T. striatus were included in the data collection instructions for each of the three protocols (Supplemental File 1). Further, the distinctive territorial calls of $T$. hudsonicus were made available through a shared Google Docs folder for use in (i). Participants were also given a photo of a pile of conifer cone scales that was made by a feeding T. hudsonicus (a good indicator of T. hudsonicus presence, which participants were also asked to observe and record).

During class point count/call broadcast surveys, classes visited a local forested area as a group to conduct one survey containing one or more point counts, during which they played recordings of $T$. hudsonicus vocalizations to elicit territorial vocal and movement responses from local squirrels. At each point count, participating classes had a four-minute quiet observation period followed by four minutes of call broadcasts of recorded T. hudsonicus territorial calls. Vocalizations were broadcast using the provided speakers working wirelessly with teachers' personal smartphones or laptop computers/tablets. The recorded T. hudsonicus territorial calls were obtained from Cornell sound library available through the Macaulay Library at the Cornell Lab of Ornithology (ML Catalogue \#numbers: 100916, 136185). Participating groups recorded specific details about the location of their survey and point counts (e.g., location in Newfoundland, habitat type), the number of $T$. hudsonicus and T. striatus that they saw and heard during both quiet and broadcast components of each point count, and the number of piles of conifer cone scales that they observed during the survey.

Data collection for parts (ii) and (iii) were designed for individual or small-group out-of-school participation. During individual walks in the woods, students completed a survey for $T$. hudsonicus and T. striatus by going for a short walk in a forest near their home and recording all observations as well as associated information about the site (same as above). During interviews with family and friends, students interviewed an adult who had a cabin in a forested area on Newfoundland or the surrounding near-shore islands. Interviewees reported whether or not T. hudsonicus or T. striatus were ever present at their cabin, how often both species were seen, and at what point in the past they first noticed each species in the area around their cabin. Participating teachers returned all completed data sheets in prepaid envelopes to the Grenfell Campus of Memorial University of Newfoundland. Updates to the participating classes were sent out as new information became available, and appropriate recognition for their work was given in presentations throughout the whole project (Elbroch et al. 2011).

\section{Assessment of individual student learning outcomes}

Schools on the west coast of Newfoundland that had classes participating in the citizen science project were contacted about an additional research opportunity. Teachers from all participating classes in schools within driving range (roughly two hours away) were contacted through e-mail. Teachers were offered \$50 per participating class to be spent on classroom enrichment. Interested teachers were given consent forms to distribute to parents or guardians, themselves, and the principals of their respective schools. Class time was then set aside roughly one week prior to participating in the PPSR so that students could complete a pre-project survey (hereafter referred to as the time- 1 
measurement) and roughly one to two weeks after participating in the PPSR for a post-project survey (hereafter referred to as the time- 2 measurement), with students indicating their assent to participate, or refusal with no consequences.

During both time 1 and time 2, students responded to a series of statements by selecting one of five response options for each statement, with matching smiley faces to aid younger students. The response options ranged from "completely true" to "not at all true." All time 1 statements had matching time 2 statements, meaning that students responded to each statement twice: once before participation in the project and once after. Multiple statements assessing the same topic will be referred to as measurement instruments in this paper. A six-item "Perception of Need Satisfaction of Science" measurement instrument was created for this study, based on theory and face-valid items, and kept brief to minimize disruption to class time. Statements included pairs of items for each psychological need: autonomy (e.g., "Scientists get to choose how they study something"), competence (e.g., "I feel that I'd be able to be a good scientist"), and relatedness (e.g., "Being a scientist means working alone"), with one reverse-scored item for each pair. A three-item "Future Intentions in Science" measurement instrument (e.g., "I would like to study science in high school") was created by modifying and truncating the Future Participation in Science subscale of the Kind, Jones, and Barmby (2007) attitudes to science measurement instrument. Similarly, a fouritem "Enjoyment of Science" measurement instrument (e.g., "Science classes are exciting") was created using the Kind, Jones, and Barmby (2007) "Learning science in school" subscale. All of the above statements had parallel mathematics versions, to act as a control school subject for changes in attitudes towards, and perceptions of, science. An additional statement related to the learning objectives for individuals was included in the time-2 statements, which asked specifically about enjoyment of the citizen science project. One demographic question was asked regarding whether participants identified as a boy, girl, or preferred not to say. See Supplemental File 2, Full List of Statements Administered to Study Participants, for the wording of the statements, or the materials available through the preregistration of the individual outcomes portion of this paper.

\section{Statistical Analysis}

For part 1 of the analysis, the assessment of project accessibility to school in rural areas, Chi-square tests were used to examine whether the proportion of participating schools classified as "rural" and requiring ferry access, differed from the proportion of schools in those categories when all schools across insular Newfoundland and the near-shore islands were considered.

To quantify individual learning outcomes, the mean responses for each of the three measurement instruments were calculated for individual students on both the science-related statements and the mathematicsrelated control statements. Larger numbers indicated more psychological need satisfaction, greater future intentions in science/mathematics, and more enjoyment of science/mathematics classes. We had a priori theoretical reasons for looking at psychological need satisfaction in aggregate (please see the pre-registered hypotheses for the study). However, the reliability of this particular measure was low (Cronbach's $\alpha$ ranged from 0.26 to 0.49). Therefore, we also examined the three components making up the psychological needs measure separately, by taking the mean of the pairs of scores representing autonomy, competence, and relatedness, for both the time- 1 and time- 2 measurements.

To examine changes in need satisfaction, future intentions in science and/or mathematics, and enjoyment of science and/or mathematics classes over time, two approaches were used. First, difference scores between time 1 and time 2 were calculated for all variables as a measure of change, with positive numbers representing positive change. Change scores for variables related to science were compared with change scores for variables related to mathematics using paired sample t-tests. This allowed for a comparison of the change in perceptions of science with a school subject that was not directly related to participants' experiences of the citizen science project.

In the second approach, paired sample t-tests were used to examine changes specifically between the time- 1 and time-2 data, specifically examining the science-related statements for predicted increases in our measures. We predicted increases in science-related variables and so considered results to be significant with a one-tailed test at the .05 criterion value (see pre-registration for the $a$ priori predicted results).

Exploratory analyses examining individual statements are also reported without correcting for multiple comparisons, and require further replication prior to having confidence in the unexpected findings. Finally, multiple regression analyses were used to examine how changes in perceptions of autonomy, competence, and relatedness in science predicted changes in future science intentions and enjoyment of science classes.

\section{Results}

\section{Programmatic outcomes}

Participants in the project included 50 teachers and 899 elementary school students affiliated with 29 schools (15\% of a total of 193 schools that were invited to participate). In total, participants submitted data from 43 class point count/call broadcast surveys (including 85 point counts), 159 individual walks in the woods, and 142 data sheets from interviews with family and friends.

Participating schools were widely distributed across insular Newfoundland and the near-shore islands. Sixtyfour percent (16 of 25) of participating schools were located in communities with populations less than 20,000 people and were more than $35 \mathrm{~km}$ from one of the two LTS outreach sites in either St. John's or Corner Brook (Figure 1), a proportion that does not differ from the 75 of 239 (31\%) of all schools classified as rural within Newfoundland (Pearson chi-square $=0.277, d f=1$, $p=0.599)$. Two of twenty-five (8\%) participating schools were located in communities requiring ferry access, a 
proportion that was not significantly different than the total 13 of 239 (5.4\%) schools requiring ferry access across Newfoundland and the near-shore islands (Pearson chisquare $=0.356, d f=1, p=0.551)$.

Overall, 80\% (163 of 204) of participant field survey efforts (class point count/call broadcast surveys and walks in the woods) resulted in students hearing or seeing an example of T. hudsonicus and/or T. striatus. Sixty-four percent (29 of 45) classes conducting point count/call broadcast surveys detected (saw and/or heard) T. hudsonicus, with 21 groups detecting squirrels during the silent portion of their point counts and 29 detecting them during the call broadcast. Seventy-seven percent (122 of 159) students who completed walks in the woods reported seeing and/or hearing T. hudsonicus, and 26\% (42) reported seeing T. striatus.

\section{Individual outcomes}

Four classes were recruited for both the time- 1 and time-2 portions of the study, with one additional class that signed up too late (after the citizen science activity) to complete the time- 1 survey and completed only the time- 2 survey. A total of 98 students were recruited: 49 boys, 40 girls, and 9 unspecified, with students in grade 4 through grade 7 . A total of 67 students completed both the pre-test and posttest survey: 33 boys, 31 girls, and 3 unspecified. Changes in degrees of freedom indicate participants excluded due to missing data.

As predicted, there was a significant change in perceived need satisfaction scores in science $\left(M_{\text {diff }}=0.04, S D=0.44\right)$ compared with mathematics $\left(M_{\text {diff }}=-0.13, S D=0.60\right)$ between the time points $(t(66)=2.22, p=0.030, d=0.27)$ (Table 1).

Separating need satisfaction into the three component needs through the pairs of measures revealed the significant change in science compared with mathematics was driven by increases in perceived competence in science $\left(M_{\text {diff }}=0.16, S D=0.77\right)$ compared with math $\left(M_{\text {diff }}=-0.16\right.$, $S D=0.86), t(66)=2.52, p=0.014, d=0.31$ ) (Table 2).

Comparisons between the two time points examining views of science (without the comparison with mathematics) failed to find a significant increase in perceived needs satisfaction (Table 3). Examining only the competence component of needs satisfaction revealed that the difference between the two time points was significant only when using a one-tailed test $\left(M_{\text {time } 1}=3.67, S D_{\text {time } 1}=0.94 ; M_{\text {time } 2}=\right.$ $\left.3.83, S D_{\text {time2 }}=0.80, t(66)=-1.68, p=0.049, d=0.21\right)$, with no significant differences in autonomy and relatedness.

Table 1: Comparison of changes in the mean values of each measurement instrument between the science and mathematics measures.

\begin{tabular}{lrrrrr} 
Variable & Change in science & Change in mathematics & $\boldsymbol{t}$ & $\boldsymbol{P}$ & Cohen's $\boldsymbol{d}$ \\
\cline { 2 - 3 } & \multicolumn{1}{c}{$\boldsymbol{M ( S D )}$} & \multicolumn{1}{c}{$\boldsymbol{M ( S D )}$} & & & \\
\hline Need satisfaction & $0.04(0.44)$ & $-0.13(0.60)$ & 2.22 & 0.030 & 0.27 \\
Future intentions & $0.11(0.83)$ & $0.08(0.67)$ & 0.23 & 0.817 & 0.03 \\
Enjoyment & $-0.05(0.75)$ & $0.00(0.87)$ & -0.33 & 0.742 & -0.04
\end{tabular}

Note: Positive values indicate greater satisfaction, intentions and enjoyment at time 2.

Table 2: Comparison of changes in participants' perceptions of three psychological needs between science and mathematics measures.

\begin{tabular}{lrrrrr} 
Variable & Change in science & Change in mathematics & $\boldsymbol{t}$ & $\boldsymbol{P}$ & Cohen's $\boldsymbol{d}$ \\
\cline { 2 - 3 } & \multicolumn{1}{c}{$\boldsymbol{M}(\mathrm{SD})$} & $\boldsymbol{M}(\mathrm{SD})$ & & & \\
\hline Relatedness & $0.07(0.74)$ & $-0.01(0.96)$ & 0.53 & 0.601 & 0.06 \\
Competence & $0.16(0.76)$ & $-0.16(0.86)$ & 2.52 & 0.014 & 0.31 \\
Autonomy & $-0.10(0.74)$ & $-0.21(0.78)$ & 1.18 & 0.243 & 0.15
\end{tabular}

Note: Positive values indicate greater satisfaction, intentions and enjoyment at time 2.

Table 3: Comparison of time-1 and time-2 values of the mean scores for each measurement instrument for the science measure.

\begin{tabular}{lccccc} 
Variable & Time 1 & Time 2 & $\boldsymbol{t}$ & $\boldsymbol{p}$ & Cohen's $\boldsymbol{d}$ \\
\cline { 2 - 4 } & $\boldsymbol{M}(\mathrm{SD})$ & $\boldsymbol{M}(\mathrm{SD})$ & & & \\
\hline Need satisfaction & $3.49(0.54)$ & $3.53(0.44)$ & 0.82 & 0.417 & 0.10 \\
Future intentions & $2.81(1.15)$ & $2.91(1.19)$ & 1.04 & 0.300 & 0.13 \\
Enjoyment & $3.73(1.13)$ & $3.68(1.16)$ & 0.52 & 0.604 & 0.06
\end{tabular}

Note: Positive values indicate greater satisfaction, intentions and enjoyment at time 2. 
An exploratory follow-up analysis revealed one item of the competence component, "I feel that I'd be able to be a good scientist," was marginally higher in the time-2 scores with a two-tailed test $(t(66)=1.69, p=0.098$, $d=0.20$ ). Participants rated themselves as having more agreement with the statement after the citizen science project $\left(M_{\text {time1 }}=3.16, S D_{\text {time1 }}=1.34\right)$ compared with before completing the project $\left(M_{\text {time2 }}=2.93, S D_{\text {time2 }}=1.27\right)$.

There was no evidence of increases in future intentions to pursue science compared with mathematics $(p=0.817)$, nor was there a change between times 1 and $2(p=0.300)$. Exploratory analyses of the individual items indicated marginally greater interest in having a job in which participants would get to do science after the project $\left(M_{\text {time2 }}=2.80, \mathrm{SD}=1.32\right)$ compared with before completing the project $\left(M_{\text {time } 1}=2.58, \mathrm{SD}=1.31 ; t(66)=1.78\right.$, $p=0.080, d=0.21)$.

Overall, students found participating in the project to be an enjoyable activity $(M=4.47, S D=1.0)$, indicating a mean response between completely true and somewhat true for "I really liked the red squirrel project." However, this enjoyment of the project did not translate into changes in enjoyment of science compared with math $(p=0.742)$, nor was there a change in enjoyment of science between times 1 and $2(p=0.604)$.

Regression analyses including changes in autonomy, competence, and relatedness as predictor variables significantly predicted changes in future intentions in science, $F(3,61)=5.37, p=0.002, R^{2}=0.21$, with change in perception of competence in science as a uniquely significant predictor, $\beta=0.45, p<0.001$ (Table 4). These variables did not significantly predict changes in enjoyment of science (all $p$ values $>0.131$ ).

Female participants reported greater positive changes in enjoyment of science $\left(M_{\text {girls }}=0.19, S D=0.62\right)$ compared with male participants $\left(M_{\text {boys }}^{\text {girls }}=-0.22, S D=0.80 ; t(61)=\right.$ 2.27, $p=0.027, d=0.57)$. However, there were no significant gender differences in the enjoyment of the citizen science project $\left(M_{\text {girls }}=4.71, S D_{\text {girls }}=0.73 ; M_{\text {boys }}=4.48\right.$, $\left.S D_{\text {boys }}=0.90 ; t(80)=1.27, p=0.207, d=0.28\right)$.

\section{Discussion}

The NSP achieved its programmatic goals, providing access to a science outreach opportunity to interested teachers and classes in Newfoundland, regardless of their rural and/or remote locations. Further, students participating in the citizen science project had a high

Table 4: Regression analyses predicting changes in participants' future intentions to participate in science.

\begin{tabular}{lcrr} 
Predictors & $\boldsymbol{B}$ & $\boldsymbol{T}$ & $\boldsymbol{p}$ \\
\hline Science relatedness & 0.07 & 0.58 & 0.565 \\
Science competence & 0.45 & 3.88 & $<0.001$ \\
Science autonomy & -0.18 & -1.59 & 0.117
\end{tabular}

$F(3,61)=5.37, p=0.002, \mathrm{R}^{2}: 0.21$ Standardized predictors were used. Two participants were excluded because of missing data. probability of experiencing firsthand encounters with local wildlife. Progress towards individual outcomes was less consistent, but there was some evidence that citizen science activity increased participants' perceptions of science as psychologically needs-satisfying, particularly with regards to competence. Many participants experienced an increase in their perceived competence as scientists, and changes in competence predicted changes in future intentions to pursue science. Student participants enjoyed the experience, with girls reporting more of a positive change in enjoyment of science than boys over the course of the project.

\section{Programmatic outcome 1: access to science outreach opportunities}

Access to informal STEM learning opportunities is a challenge for children in rural communities, where distance can severely limit access to in-person programs (Avery 2013; Hartman, Hines-Bergmeier, and Klein 2017). Hartman, Hines-Bergmeier, and Klein (2017) further suggest that collaboration between teachers in rural communities and informal STEM educational entities (such as libraries, museums, 4H, etc.) (Russell, Knutson, and Crowley 2013) provides a mechanism to increase students' accessibility to STEM learning opportunities. The partnership between LTS and local teachers to complete the NSP provides an example of this kind of partnership and appears to have been successful in that being in a rural location was not an impediment to participation.

\section{Programmatic outcome 2: encounters with wildlife}

There is little research on how direct encounters with wildlife through PPSR may impact the experiences and learning outcomes of participants, but substantial research has examined the effects of encounters with live animals on participants of wildlife tourism (where wildlife is both captive and wild) (Ballantyne and Packer 2005; Fuhrman and Ladewig 2008), as well as the potential benefits of using living animals in children's science education (Watson 2006; Hummel and Randler 2012; Schönfelder and Bogner 2018). In the context of wildlife tourism, exposure to live animals can result in strong emotional responses by participants (Ballantyne, Packer, and Sutherland 2011) and increased participant knowledge (Adelman, Falk, and James 2000), and, rarely, can promote conservation-oriented behavioural changes (Ballantyne and Packer 2005).

There is mixed evidence for the value of live animals in science education (Hummer and Randler 2012), but benefits are more frequently reported as increases in affective factors rather than cognitive ones (e.g., Ballouard et al. 2012). After engaging in learning with live animals, children demonstrated greater feelings of wellbeing, lower feelings of boredom (Hummel and Randler 2010; Schonfelder and Bogner 2018), and some greater feelings of interest (Hummer and Randler 2012) than when engaged in similar experiences without animals. Even short (one-day) field experiences using live animals may impact students' perspectives (Ballouard et al. 2012). In this context, the high incidence of participants in the NSP to see live $T$. hudsonicus and T. striatus is likely an 
important and impactful feature of the project. Even for students who did not physically see or hear a squirrel, conducting fieldwork outdoors may have been beneficial. Access to direct learning about nature through field experiences can increase students' reported connectedness to nature (Liefländer et al. 2013) and their likelihood of translating new knowledge to behaviours (Duerden and Witt 2010).

Animal activity and close proximity to animals are both positive features of wildlife encounters for many participants of wildlife tourism (Margulis, Hoyos, and Anderson 2003; Ballantyne, Packer, and Sutherland 2011). Similarly, Ballouard et al. (2012) found that students most valued the chance to have close proximity to wildlife (in their case, handling snakes). Correspondingly, the use of wireless speakers to conduct call broadcasts and elicit territorial responses from $T$. hudsonicus is a particularly important component of the NSP, as these responses often involve the squirrel approaching the speaker and being active (Warkentin et al. in prep). The wireless speakers were relatively low cost (<US\$10 per item), were easy to use, and were a valuable addition to the project.

\section{Individual outcomes}

The findings from the individual outcomes portion of the study revealed connections between how students perceived science as providing opportunities to fulfill their psychological needs, and their enjoyment and future intentions to explore careers in science. Although the correlational nature of our study design prevents us from making causal claims, our measurements indicated that students tended to increase or maintain their positive views of science, particularly when compared with mathematics as a school subject not directly related to the project. Not all parts of our hypotheses were fully supported, which may be partly because of specific features of the NSP, and partly because of methodological limitations.

The stronger change in the competence component of psychological need satisfaction as compared with the other components may be partially explained by the study methodology. Most of the statements in the measurement instruments asked for views about scientists in general, to gauge how students' views of scientists had changed; however, the competence component contained the sole statement regarding psychological needs that was specifically about each student: "I feel that I'd be able to be a good scientist." The responses to this statement had the strongest evidence for change in response to the citizen science project, and the statement was related to enjoyment of science and future science intentions. Participating in the citizen science activity may have had the strongest impact on this variable owing to the "perceived realness" of the project. Previous research has found that changing students' views of science depends on the extent to which students perceive they are contributing to a real science project (Ballard, Dixon, and Harris 2017). This project was ideal for changing students' views of believing that they themselves could do science because it provided them a relatively rare opportunity to collect original data for an authentic science project.
Part of the reason that the responses to the "I feel that I'd be able to be a good scientist" statement changed between times 1 and 2, while the statements assessing views of scientists in general had relatively little movement, may have to do with the one-off nature of this particular activity. Changing students' views about themselves may be easier than changing their views of scientists in general, which requires more extrapolation, and potentially more exposure. It would be valuable for future researchers to study student participants over a longer period of time, taking part in a project that spans weeks or months. Falk and colleagues (2012) argue about students' engagement with science over time, with other researchers finding that longer projects have stronger impacts than we report (e.g., Bogner 1998; Bodzin 2008; Braun, and Dierkes 2017).

The importance of the "good scientist" statement extends beyond SDT, and is related to other work showing the importance of direct experiences with science in influencing self-efficacy, a closely related concept to competence (Sheu et al. 2018). Self-efficacy in science has a role in increasing scientific achievement (Talsma et al. 2018) and can predict student motivation to have a career in science (Jansen, Scherer, and Schroeders 2015)-a conclusion that matches our finding that changes in perceived competence predicted future intentions to pursue science. Future citizen science projects for school children may wish to find further ways to facilitate a sense of competence in participants.

The absence of evidence for participants seeing science as fulfilling autonomy or relatedness needs may be due to the structure of the project. Participants in the NSP received and followed specific instructions for data collection (a "contributory" project; Bonney et al. 2009), so there was no opportunity to experience autonomy in a scientific context. Increased participant involvement in project design and flexibility in approaches to data collection (e.g., "collaborative" or "co-created" projects; Bonney et al. 2009) are promoted in recent literature on citizen science (e.g., Stevens et al. 2014; Kennett, Danielsen, and Silvius 2015; Lukyanenko, Parsons, and Wiersma 2016) and supported by empirical examples such as the volunteer-led discovery of the Green Pea galaxies (Straub 2016).

Similarly, although the NSP had a group component (the class point count/call broadcast surveys), much science learning in a school environment is already occurring in a group context. Participating students likely had other opportunities to work together in a scientific context and so the group-work component of the NSP may not have been a novel experience and consequently did not change their perceptions of the relatedness component of doing science. To increase participants' feelings of autonomy and relatedness while doing science, future projects may provide more opportunities for participants to play an active role in scientific decision-making. This may include actively involving students in the generation of hypotheses/study design, perhaps in small teams guided by teachers through a Socratic style of questioning that ultimately leads students to an effective design. This style of helping is called "autonomy support" in the psychological literature, and provides ways to assist those 
who need help without undermining their sense of autonomy (Reeve and Jang 2006).

Although there was no general increase in enjoyment of science classes, students reported greatly enjoying the citizen science project. Part of the reason for this discrepancy could be in how students perceived the activity. If students viewed the activity as a unique event, it may not have changed their perception of their regular science classes, or science in general. More opportunities for students to engage in real science activities, from guided generation of hypotheses, through to data collection techniques may have a more substantial impact, though future researcherteacher teams are needed to study this possibility.

Psychological needs satisfaction is just one predictor of future science behaviour, and one of likely multiple mechanisms through which participating in citizen science projects may affect students' attitudes, intentions, and future behaviour regarding science classes. In addition to the theories and findings we've already discussed, scholars have identified other key predictors of students' future engagement with science, such as "Science capital" (e.g., Archer et al. 2015), "Science Identity" (Stets et al. 2017), and potential issues with feelings of belonging in STEM (Rainey et al. 2018). All play important roles in predicting students' future engagement in science. Future research should continue to explore how these different predictors are influenced by participation in citizen science activities, and conversely, how these activities may be structured in ways to increase students' future engagement.

Many of the recommendations arising from the "Individual Outcomes" part of the NSP suggest increasing opportunities for students to participate in all elements of project design. There is a further pedagogical argument for involving students in curriculum-linked citizen science projects that are collaborative or co-created. The NSP was reliant on participants' local rural knowledge (Avery and Kassam 2011; e.g., the location of local trails, historical sightings of squirrels at known locations, etc.) and incorporates elements of place-based/conscious education (PBE), a pedagogical practice that strives to "ground learning in local phenomena and students' lived experiences" (Smith 2002). PBE serves the dual purpose of valuing and legitimizing students' pre-existing knowledge about their local environment (Avery 2013), and framing scientific concepts and principles as relevant to their lives (Gardner et al. 2015). The contributory nature of the NSP causes it to fall short of the more developed definition of PBE, which includes a critical pedagogy of place (Gruenewald 2003), and encourages students to critically assess, critique, and challenge the circumstances within their place. Involving students in collaborative or co-created citizen science projects would allow them greater agency and likely be more conducive to a true PBE scenario (e.g., Karrow and Fazio 2010).

In fact, we believe that much of the subject matter associated with the NSP-the introduction of non-native species and their subsequent ecological disturbances-is rife for critical consideration and that a future iteration of the NSP could serve as a strong example of PBE. Smith (2007) discusses students in Oregon critically assessing the reintroduction of wolves to their state by considering a range of different perspectives and data. Students in Newfoundland could similarly balance the rationale for the introduction of T. hudsonicus to Newfoundland (as a fur-bearing mammal and natural prey source; Whitaker [2015]), with the detrimental impacts of this species on other, native species.

\section{Conclusions}

Participants in the NSP included classes in schools from across insular Newfoundland and the near-shore islands. The project resulted from a successful partnership between formal and informal science educators and was equally accessible to all schools, regardless of distance from an urban centre/LTS site. Most students participating in data collection experienced firsthand encounters with one or both of the study species, likely increasing the impact of the experience and also providing proof-of-concept that squirrel surveys using call broadcast techniques can be successfully employed by citizen scientists. There was limited evidence that participants experienced an increased sense of science as satisfying psychological needs, although findings suggest an increase in perceived competence following study participation. The relationship between changes in perceived competence and changes in future intentions towards science highlights the potential motivational benefits of participating in citizen science projects. Projects that foster participants' perceived scientific abilities may inspire them to continue their involvement, and seek out new opportunities in science.

\section{Note}

${ }^{1}$ The materials and a brief description of the hypothesized relationships were preregistered on the Open Science Framework, in accordance with current best practices in social psychology. As practices have continued to evolve, this preregistration provides only brief descriptions of the study, planned analyses and hypotheses. The preregistration can be viewed here: https://osf.io/j7f4u/?view_only=470237393eda4d6c bbf28fe11030d91a.

\section{Additional Files}

The additional files for this article can be found as follows:

- Supplemental File 1. Teacher's Guide to the Newfoundland Squirrel Project. DOI: https://doi. org/10.5334/cstp.275.s1

- Supplemental File 2. Full list of statements administered to study participants. DOI: https://doi. org/10.5334/cstp.275.s2

\section{Ethics and Consent}

All work was conducted with permission from the Newfoundland and Labrador English School District school board, as well as with necessary provincial permitting for conducting wildlife research (Scientific research permit \#: WLR2016-18) and approval from the Memorial University of Newfoundland animal care committee (Animal care approval \#16-05EF). The student survey portion of the study was separately approved by each participat- 
ing teacher and school principal; informed consent was also given by parents, with participating students providing assent. This portion of the study was approved by the Grenfell Campus Research Ethics Board (file \#: 20170687).

\section{Acknowledgements}

We thank teachers and students in the Newfoundland and Labrador English School District for their work collecting data and participating in the Newfoundland Squirrel Project (NSP). We further thank Let's Talk Science (LTS) for their support in producing and delivering the project. Substantial help in data collection and entry for the human survey portion of this project was provided by Shelbie Anderson and Bethany Bernier, with additional help from Kendra Wimbleton. Funding for the NSP was provided by LTS, Memorial University of Newfoundland (Memorial University Career Enhancement Program, and an Office of Public Engagement Quick Start grant), and the Canadian federal government through a Canada Summer Jobs position. Marina Milyavskaya provided consultation early on for the individual outcomes portion of the study. We further acknowledge two anonymous reviewers, whose suggestions greatly improved the quality of this manuscript.

\section{Funding Information}

The Newfoundland Squirrel Project was funded by Let's Talks Science, Memorial University of Newfoundland (Memorial University Career Enhancement Program grants, Office of Public Engagement Quick Start Grant), and the Government of Canada (Canada Summer Jobs grant). Memorial University's MUCEP program was used to support the individual outcomes data collection portion of this project, through hiring Shelbie Anderson who led a small team of volunteer research assistants, including Bethany Bernier and Kendra Wimbleton.

\section{Competing Interests}

The authors have no competing interests to declare.

\section{Author Contributions}

All authors contributed to project design, data collection, data analysis, and writing and editing the subsequent manuscript.

\section{References}

Adelman, LM, Falk, JH and James, S. 2000. Impact of national aquarium in Baltimore on visitors' conservation attitudes, behavior, and knowledge. Curator, 43(1): 33-61. DOI: https://doi. org/10.1111/j.2151-6952.2000.tb01158.x

Archer, L, Dawson, E, DeWitt, J, Seakins, A and Wong, B. 2015. "Science capital": A conceptual, methodological, and empirical argument for extending bourdieusian notions of capital beyond the arts. Journal of Research in Science Teaching, 52(7): 922-948. DOI: https://doi.org/10.1002/tea.21227

Avery, LM. 2013. Rural science education: Valuing local knowledge. Theory into Practice, 52(1): 28-35. DOI: https://doi.org/10.1080/07351690.2013.743769
Avery, LM and Kassam, K-AS. 2011. Phronesis: Children's local rural knowledge of science and engineering. Journal of Research in Rural Education, 26(2): 1-18.

Ballantyne, R and Packer, J. 2005. Promoting environmentally sustainable attitudes and behavior through free-choice learning experiences: What is the state of the game? Environmental Education Research, 11(3): 281-295. DOI: https:// doi.org/10.1080/13504620500081145

Ballantyne, R, Packer, J and Sutherland, LA. 2011. Visitors' memories of wildlife tourism: Implications for the design of powerful interpretive experiences. Tourism Management, 32: 770-779. DOI: https://doi. org/10.1016/j.tourman.2010.06.012

Ballard, HL, Dixon, CGH and Harris, EM. 2017. Youthfocused citizen science: Examining the role of environmental learning and agency for conservation, 208: 65-75. DOI: https://doi.org/10.1016/j.biocon.2016.05.024

Ballouard, J-M, Provost, G, Barré, D and Bonnet, X. 2012. Influence of a field trip on the attitude of schoolchildren toward unpopular organisms: An experience with snakes. Journal of Herpetology, 46(3): 423-428. DOI: https://doi.org/10.1670/11-118

Benkman, CW. 1993. The evolution, ecology, and decline of the Red Crossbill of Newfoundland. Science, 47(2): 225-229.

Bodzin, AM. 2008. "Integrating Instructional Technologies in a Local Watershed Investigation with Urban Elementary Learners". The Journal of Environmental Education, 39(2): 47-58. DOI: https://doi. org/10.3200/JOEE.39.2.47-58

Bogner, FX. 1998. "The Influence of Short-term Outdoor Ecology Education on Long-term Variables of Environmental Perspective". The Journal of Environmental Education, 29(4): 17-29. DOI: https://doi. org/10.1080/00958969809599124

Bonney, R, Ballard, H, Jordan, R, McCallie, E, Phillips, T, Shirk, J and Wilderman, CC. 2009. Public participation in scientific research: Defining the field and assessing its potential for informal science education. A CAISE Inquiry Group Report. Washington, DC: Center for Advancement of Informal Science Education (CAISE).

Bonney, R, Phillips, TB, Ballard, HL and Enck, JW. 2016. Can citizen science enhance public understanding of science? Public Understanding of Science, 25(1): 2-16. DOI: https://doi.org/10.1177/0963662515607406

Braun, T and Dierkes, P. 2017. Connecting Students to Nature - How Intensity of Nature Experience and Student Age Influence the Success of Outdoor Education Programs. Environmental Education Research, 23(7): 937-949. DOI: https://doi.org/10.1080/13504622.2 016.1214866

Brossard, D, Lewenstein, B and Bonney, R. 2005. Scientific knowledge and attitude change: The impact of a citizen science project. International Journal of Science Education, 27(9): 1099-1121. DOI: https:// doi.org/10.1080/09500690500069483 
Cronje, R, Rohlinger, S, Crall, A and Newman, G. 2011. Does participation in citizen science improve scientific literacy? A study to compare assessment methods. Applied Environmental Education \& Communication, 10(3): 135-145. DOI: https://doi.org/10.1080/15330 15X.2011.603611

Dawson, E. 2014. Equity in informal science education: Developing an access and equity framework for science museums and science centres. Studies in Science Education, 50(2): 209-247. DOI: https://doi.org/10.10 80/03057267.2014.957558

Deci, EL and Ryan, RM. 2012. Self-Determination Theory. In: Van Lange, PAM, Kruglanski, AQ and Higgins, ET (eds.), Handbook of theories of social psychology, 1: 416-437. CA: Sage. DOI: https://doi.org/10.4135/9781446249215.n21

Devictor, V, Whittaker, RJ and Beltrame, C. 2010. Beyond scarcity: Citizen science programmes as useful tools for conservation biogeography. Diversity and Distributions, 16(3): 354-362. DOI: https://doi. org/10.1111/j.1472-4642.2009.00615.x

Duerden, MD and Witt, PA. 2010. The impact of direct and indirect experiences on the development of environmental knowledge, attitudes, and behavior. Journal of Environmental Psychology, 30: 379-392. DOI: https://doi.org/10.1016/j.jenvp.2010.03. 007

Elbroch, M, Mwampamba, TH, Santos, MJ, Zylberberg, M, Liebenberg, L, Minye, J, Mosser, C and Reddy, E. 2011. The value, limitations, and challenges of employing local experts in conservation research. Conservation Biology, 25(6): 1195-1202. DOI: https://doi. org/10.1111/j.1523-1739.2011.01740.x

Evans, C, Abrams, E, Reitsma, R, Roux, K, Salmonsen, L and Marra, PP. 2005. The Neighbourhood Nestwatch Program: Participant outcomes of a citizen-science ecological research project. Conservation Education, 19(3): 58-594. DOI: https://doi.org/10.1111/j.15231739.2005.00s01.x

Fuhrman, NE and Ladewig, H. 2008. Characteristics of animals used in zoo interpretation: A synthesis of research. Journal of Interpretation Research, 13(2): 31-42.

Gardner, GE, Karl, C, Ferzli, M, Shea, D, Haase, D and Day, JB. 2015. The Bennett's Millpond environmental learning project: Place-based education with studentteacher research teams. In: Stratton, SK, Hagevik, R, Feldman, A and Bloom, M (eds.), Educating science teachers for sustainability, 255-274. Switzerland: Springer. DOI: https://doi.org/10.1007/978-3-31916411-3_14

Gosse, J, Hermanutz, L, McLaren, B, Deering, P and Knight, T. 2011. Degradation of boreal forests by nonnative herbivores in Newfoundland's National Park: Recommendations for ecosystem restoration. Natural Areas Journal, 31: 331-339. DOI: https://doi. org/10.3375/043.031.0403

Gruenewald, DA. 2003. The best of both worlds: A critical pedagogy of place. Educational Researcher,
32(4): 3-12. American Educational Research Journal, 40(3): 619-654. DOI: https://doi. org/10.3102/0013189X032004003

Hartman, SL, Hines-Bergmeier, J and Klein, R. 2017. Informal STEM Learning: The state of research, access and equity in rural early childhood settings. Science Education and Civic Engagement, 9(2): 32-39. DOI: https://doi.org/10.1179/10598650 15Z.000000000105

Hillier, SE and Kitsantis, A. 2014. The effect of a horseshoe crab citizen science program on middle school student science performance and STEM career motivation. School Science and Mathematics, 114(6): 302-310. DOI: https://doi.org/10.1111/ssm.12081

Holck, MH. 2008. Participatory forest monitoring: An assessment of the accuracy of simple cost-effective methods. Biodiversity and Conservation, 17(8): 2023-2036. DOI: https://doi.org/10.1007/s10531007-9273-4

Hummel, E and Randler, C. 2010. Experiments with living animals - effects on learning success, experimental competency and emotions. Procedia Social and Behavioral Sciences, 2: 3823-3830. DOI: https://doi. org/10.1016/j.sbspro.2010.03.597

Hummel, E and Randler, C. 2012. Living animals in the classroom: A meta-analysis on learning outcome and a treatment-control study focusing on knowledge and motivation. Journal of Science Education and Technology, 21: 95-105. DOI: https://doi.org/10.1007/ s10956-011-9285-4

Jansen, M, Scherer, R and Schroeders, U. 2015. Students' self-concept and self-efficacy in the sciences: Differential relations to antecedents and educational outcomes. Contemporary Educational Psychology, 41: 13-24. DOI: https://doi.org/10.1016/j. cedpsych.2014.11.002

Jordan, RC, Ballard, HL and Phillips, TB. 2012. Key issues and new approaches for evaluating citizenscience learning outcomes. Frontiers in Ecology and the Environment, 10(6): 307-309. DOI: https://doi. org/10.1890/110280

Karrow, D and Fazio, X. 2010. Education-withinplace: Care, citizen science, and EcoJustice. In: Tippins, DJ (ed.), Cultural Studies of Science Education, 3: 193-214. Springer Science+Business Media B.V. DOI: https://doi.org/10.1007/978-90-481-39293_16

Kennett, R, Danielsen, F and Silvius, KM. 2015. Citizen science is not enough on its own. Nature, 521: 161. DOI: https://doi.org/10.1038/521161d

Kind, P, Jones, K and Barmby, P. 2007. Developing attitudes towards science measures. International Journal of Science Education, 29(7): 871-893. DOI: https://doi. org/10.1080/09500690600909091

Kountoupes, DL and Oberhauser, KS. 2008. Citizen science and youth audience: Educational outcomes of the Monarch larva monitoring project. Journal of Community Engagement and Scholarship, 1(1): 10-20. 
Lavigne, GL, Vallerand, RJ and Miquelon, P. 2007. A motivational model of persistence in science education: A self-determination theory approach. European Journal of Psychology of Education, 22(3): 351. DOI: https://doi.org/10.1007/BF03173432

Lewandowski, E and Specht, H. 2015. Influence of volunteer and project characteristics on data quality of biological surveys. Conservation Biology, 29(3): 713-723. DOI: https://doi.org/10.1111/cobi.12481

Liefländer, AK, Fröhlich, G, Bogner, FX and Schultz, W. 2013. Promoting connectedness with nature through environmental education. Environmental Education Research, 19(3): 370-384. DOI: https://doi.org/10.10 80/13504622.2012.697545

Lukyanenko, R, Parsons, J and Wiersma, YF. 2016. Emerging problems of data quality in citizen science. Conservation Biology, 30(3): 447-449. DOI: https:// doi.org/10.1111/cobi.12706

Margulis, SW, Hoyos, C and Anderson, M. 2003. Effect of felid activity on zoo visitor interest. Zoo Biology, 22: 587-599. DOI: https://doi.org/10.1002/zoo.10115

Milyavskaya, M, Nadolny, D and Koestner, R. 2014. Where do self-concordant goals come from? The role of domain-specific psychological need satisfaction. Personality and Social Psychology Bulletin, 40(6): 700-711. DOI: https://doi.org/10.1177/0146167214524445

Niemiec, CP and Ryan, RM. 2009. Autonomy, competence, and relatedness in the classroom: Applying self-determination theory to educational practice. Theory and Research in Education, 7(2): 133-144. DOI: https://doi.org/10.1177/1477878509104318

Pandya, RE. 2012. A framework for engaging diverse communities in citizen science in the US. Frontiers in Ecology and the Environment, 10(6): 314-317. DOI: https://doi.org/10.1890/120007

Phillips, T, Porticella, N, Constas, $\mathbf{M}$ and Bonney, R. 2018. A Framework for articulating and measuring individual learning outcomes from participation in citizen science. Citizen Science: Theory and Practice, 3(2): 3. DOI: https://doi.org/10.5334/cstp.126

Rainey, K, Dancy, M, Mickelson, R, Stearns, E and Moller, S. 2018. Race and gender differences in how sense of belonging influences decisions to major in STEM. International Journal of STEM Education, 5(1): 10. DOI: https://doi.org/10.1186/s40594-018-0115-6

Reeve, J and Jang, H. 2006. What teachers say and do to support students' autonomy during a learning activity. Journal of Educational Psychology, 98(1): 209. DOI: https://doi.org/10.1037/0022-0663.98.1.209

Russell, JL, Knutson, K and Crowley, K. 2013. Informal learning organizations as part of an educational ecology: Lessons from collaboration across the formal-informal divide. Journal of Education Change, 14: 259-281. DOI: https://doi.org/10.1007/s10833-0129203-4

Ryan, RM and Deci, EL. 2000. Intrinsic and extrinsic motivations: Classic definitions and new directions. Contemporary Educational Psychology, 25(1): 54-67. DOI: https://doi.org/10.1006/ceps.1999.1020

Schönfelder, ML and Bogner, FX. 2018. How to sustainably increase students' willingness to protect pollinators. Environmental Education Research, 24(3): 461-473. DOI: https://doi.org/10.1080/13504622.20 17.1283486

Sheu, HB, Lent, RW, Miller, MJ, Penn, LT, Cusick, ME and Truong, NN. 2018. Sources of self-efficacy and outcome expectations in science, technology, engineering, and mathematics domains: A meta-analysis. Journal of Vocational Behavior, 109: 118-136. DOI: https://doi.org/10.1016/j.jvb.2018.10.003

Sipple, JW and Brent, BO. 2015. Challenges and strategies associated with rural school settings. In: Handbook of research in education finance and policy, second edition. Ladd, HF and Fiske, EB (eds.), 607622. Routledge.

Smith, GA. 2002. Place-based education: Learning to be where we are. Phi Delta Kappan, 83(8): 584-594. DOI: https://doi.org/10.1177/003172170208300806

Smith, GA. 2007. Place-based education: Breaking through the constraining regularities of public school. Environmental Education Research, 13(2): 189-207. DOI: https://doi.org/10.1080/13504620701285180

Snäll, T, Kindvall, O, Nilsson, J and Pärt, T. 2011. Evaluating citizen-based presence data for bird monitoring. Biological Conservation, 144(2): 804-810. DOI: https://doi.org/10.1016/j.biocon.2010.11.010

Statistics Canada. 2016. Population counts, for Canada, provinces and territories, census divisions, population centre size groups and rural areas, 2016 Census - 100\% data (table). Population and dwelling count highlight tables, 2016 Census. Last updated February 20, 2019. https://www12.statcan.gc.ca/census-recensement/2016/dp-pd/hlt-fst/pd-pl/Table.cfm?Lang=En $\mathrm{g} \& \mathrm{~T}=703 \& \mathrm{SR}=1 \& S=87 \& \mathrm{O}=\mathrm{A} \& \mathrm{RPP}=25$ (accessed September 10, 2019).

Stets, JE, Brenner, PS, Burke, PJ and Serpe, RT. 2017. The science identity and entering a science occupation. Social Science Research, 64: 1-14. DOI: https:// doi.org/10.1016/j.ssresearch.2016.10.016

Stevens, M, Vitos, M, Altenbuchner, J, Conquest, G, Lewis, J and Haklay, M. 2014. Taking participatory citizen science to extremes. IEEE Pervasive Computing, 13(2): 20-29. DOI: https://doi.org/10.1109/ MPRV.2014.37

Straub, MCP. 2016. Giving citizen scientists a chance: A study of volunteer-led scientific discovery. Citizen Science: Theory and Practice, 1(1): 1-10. DOI: https:// doi.org/10.5334/cstp.40

Strong, JS and Leroux, SJ. 2014. Impact of non-native terrestrial mammals on the structure of the terrestrial mammal food web of Newfoundland, Canada. PLoS ONE, 9(8): 1-10. DOI: https://doi.org/10.1371/journal.pone.0106264

Talsma, K, Schüz, B, Schwarzer, R and Norris, K. 2018. I believe, therefore I achieve (and vice versa): A metaanalytic cross-lagged panel analysis of self-efficacy and academic performance. Learning and Individual Differences, 61: 136-150. DOI: https://doi.org/10.1016/j. lindif.2017.11.015

Trumbull, DJ, Bonney, R, Bascom, D and Cabral, A. 2000. Thinking scientifically during participation in a citizen-science project. Informal Science, 84: 
265-275. DOI: https://doi.org/10.1002/(SICI) 1098237X(200003)84:2<265::AID-SCE7>3.0.CO;2-5

Vitone, T, Stoler, KA, Steininger, MS, Huler, J, Dunn, R and Lucky, A. 2016. School of ants goes to college: Integrating citizen science into the general education classroom increases engagement with science. Journal of Science Communication, 15(1): 1-24. DOI: https:// doi.org/10.22323/2.15010203

Warkentin, IG, Spicer, HE, McDermott, JPB, Whitaker, DM and Fraser, EE. In preparation. Influences on detection probability of red squirrels across seasons using vocalization broadcast.

Watson, G. 2006. Wild becomings: How the everyday experience of common wild animals at summer camp acts as an entrance to the more-than-human world. Canadian Journal of Environmental Education, 11(1): 127-142.

Whitaker, DM. 2015. The colonization of Newfoundland by red squirrels (Tamiasciurus hudsonicus). Osprey: Nature Journal of Newfoundland and Labrador, 46: 23-29.

Whitaker, DM, Taylor, PD and Warkentin, IG. 2015. Gray-cheeked Thrush (Catharus minimus minimus) distribution and habitat use in a montane forest landscape of western Newfoundland, Canada. Avian Conservation and Ecology, 10(2): DOI: https://doi.org/10.5751/ACE-00778-100 204

How to cite this article: Spicer, H, Nadolny, D and Fraser, E. 2020. Going Squirrelly: Evaluating Educational Outcomes of a Curriculum-aligned Citizen Science Investigation of Non-native Squirrels. Citizen Science: Theory and Practice, 5(1): 14, pp. 1-13. DOl: https://doi.org/10.5334/cstp.275

Submitted: 13 September $2019 \quad$ Accepted: 30 May $2020 \quad$ Published: 15 July 2020

Copyright: (c) 2020 The Author(s). This is an open-access article distributed under the terms of the Creative Commons Attribution 4.0 International License (CC-BY 4.0), which permits unrestricted use, distribution, and reproduction in any medium, provided the original author and source are credited. See https://creativecommons.org/licenses/by/4.0/.

$\mathrm{u}[\quad$ Citizen Science: Theory and Practice is a peer-reviewed open access journal published by Ubiquity Press. 